\title{
FISIKOKIMIA MADU MULTIFLORA ASAL RIAU DAN POTENSINYA SEBAGAI ANTIBAKTERI Escherichia coli DAN Staphylococcus aureus
}

\author{
Akhmad Endang Zainal Hasan ${ }^{1}$, Heny Herawati ${ }^{2}$, Purnomo ${ }^{3}$, Lathifah Amalia ${ }^{1}$ \\ ${ }^{1}$ Departemen Biokimia Fakultas Matematika dan Ilmu Pengetahuan Alam, Institut Pertanian Bogor \\ ${ }^{2}$ Balai Penelitian PascaPanen, LitBang Pertanian \\ ${ }^{3}$ Balai Penelitian Hutan
}

\begin{abstract}
ABSTRAK
Madu merupakan cairan alami yang telah banyak dimanfaatkan oleh masyarakat luas. Tujuan penelitian ini mengidentifikasi karakteristik madu multiflora asal Riau secara fisik maupun kimiawi sesuai dengan standar Nasional serta efektifitasnya terhadap Escherichia coli dan Staphylocccus aureus. Hasil yang diperoleh terdapat 2 madu dari 12 sampel madu memiliki karakteristik sesuai dengan Standar Nasional Indonesia (SNI) yaitu madu PLW1 dan RHU4. Madu yang terpilih berdasarkan parameter kadar air, HMF, kadar gula pereduksi, serta kadar abu adalah RHU4, PLW1, RHI2 dan RHI1. Madu RHU4 memiliki kadar air terendah sebesar $16.45 \%$ dan madu RHI2 sebesar $20.56 \%$. Madu RHU4 memiliki kadar abu paling rendah sebesar $0.01 \%$ dan tertinggi madu RHI2 sebesar $1.01 \%$. Madu dengan kadar gula pereduksi terendah adalah madu RHI1 sebesar $69.41 \%$ dan tertinggi madu BKL1 sebesar 95.37\%. Madu RHI1 memiliki kadar HMF yang paling rendah yaitu 0.70 dan tertinggi madu RHU1 yaitu 82.67. Zona hambat paling kecil untuk Staphylococcus aureus yaitu sebesar $7.84 \mathrm{~mm}$ pada madu RHI1 20\% sedangkan Zona hambat terbesar pada madu RHI2 80\% sebesar $19.25 \mathrm{~mm}$. Zona hambat terkecil Escherichia coli pada madu RHI1 konsentrasi $40 \%$ sebesar $1.22 \mathrm{~mm}$, sedangkan zona hambat terbesar pada madu PLW1 60\% sebesar $4.58 \mathrm{~mm}$.
\end{abstract}

Kata kunci: gula pereduksi, HMF, kadar air, kadar abu, madu.

\section{ABSTRACT}

Honey is a natural liquid that has been widely used by the public. The purpose of this study was to identify physical and chemical characteristics of multiflora honey from Riau in accordance with National standards and its effectiveness against Escherichia coli and Staphylocccus aureus. The results obtained were 2 honeys from 12 honey samples having characteristics in accordance with the Indonesian National Standard (SNI), namely PLW1 and RHU4 honey. The selected honey based on parameters of moisture content, HMF, reducing sugar content, and ash content are RHU4, PLW1, RHI2 and RHI1. RHU4 honey has the lowest water content of $16.45 \%$ and RHI2 honey of $20.56 \%$. RHU4 honey has the lowest ash content of $0.01 \%$ and the highest RHI2 honey of $1.01 \%$. The honey with the lowest reducing sugar content was RHI1 honey at $69.41 \%$ and the highest was BKL1 honey at $95.37 \%$. RHI1 honey had the lowest HMF content of 0.70 and the highest was RHU1 honey, namely 82.67 . The smallest inhibition zone for Staphylococcus aureus was $7.84 \mathrm{~mm}$ for $20 \%$ RHI1 honey, while the largest inhibition zone for RHI2 $80 \%$ honey was $19.25 \mathrm{~mm}$. The smallest inhibition zone of Escherichia coli in RHI1 honey with a concentration of $40 \%$ was $1.22 \mathrm{~mm}$, while the largest inhibition zone in PLW1 $60 \%$ honey was 4.58 $\mathrm{mm}$.

Keywords : reducing sugar content, HMF content, moisture content, ash content, honey

\section{PENDAHULUAN}

Madu adalah cairan alami umumnya mempunyai rasa manis yang dihasilkan oleh lebah madu (Apis sp.) dari sari bunga tanaman (floral nektar) atau bagian lain tanaman (ekstra floral) (BSN 2013). Menurut Gairola et al., (2013), madu merupakan bahan makanan yang kompleks yang diproduksi dari sarang lebah dan dapat digunakan manusia sebagai agen pemanis tanpa adanya proses pengolahan. Berbagai senyawa antara lain yaitu air, mineral, karbohidrat dalam bentuk gula, asam organik, vitamin, enzim dan senyawa bioaktif (Wilkinson \& Cavanagh, 2005). Enzim yang utama dalam madu antara lain yaitu invertase, diastase dan karbohidrat oksidase (Nadhilla, 2014). Menurut BSN (2013), kadar gula pereduksi pada madu yaitu minimal $65 \%$. Madu memiliki kadar air yang rendah, namun madu juga memiliki sifat higroskopis yaitu dapat menyerap air dan kelembaban udara di sekitarnya (Suranto, 2007). Madu memiliki warna, aroma serta rasa yang berbeda-beda, tergantung pada jenis tanaman yang banyak tumbuh di sekitar peternakan lebah madu. Senyawa bioaktif dalam madu beragam seperti senyawa antibakteri, antioksidan, antifungi, antiviral membuat madu banyak digunakan sebagai obat. Menurut Singh et al., (2012), madu dapat digunakan sebagai obat yang 
lengkap sebagai agen antibakteri, antifungal, antiviral dan antioksidan.

Gairola et al., (2013) melakukan penelitian terkait karakteristik fisikokimiawi madu Apis cerana - Indica $f$. dari daerah Uttarkashi, Uttarakhand, India. Penelitian karakteristik fisikokimia juga dilakukan pada madu Bangka dan madu kemasan yang dipasarkan di Kota Palembang (Evahelda $d k k$., 2015). Salah satu parameter adalah HMF, karena madu dengan kandungan gula heksosa akan beruabah menjadi HMF bila mengalami pemanasan (Chua et al., 2014). Kadar air madu dapat disesuaikan dengan cara adsorption drying (Maliaentika $d k k$ 2016). Keuntungan dari madu hasil humidifier adalah tidak terdapat perbedaan kapasitas antioksidan, total fenolik kandungan, flavonoid, rasa, warna, penerimaan, dan niat membeli produk serta proses dehumidifikasi madu tidak merusak kualitas sensorik (Aroucha et al., 2019).

'Brand' madu multiflora umumnya sesuai dengan lokasi dikumpulkannya madu seperti madu Sumbawa, madu Riau, madu Danau Sentarum atau madu Bangka. Menurut Kuntadi (2008), rata-rata produksi madu seluruh Indonesia diperkirakan mencapai sekitar 4000 ton setiap tahunnya. Produksi yang dihasilkan tersebut sekitar $75 \%$ dari perburuan madu liar di hutan. Hampir seluruh wilayah Indonesia merupakan daerah yang potensial sebagai produsen madu.

Daerah yang menjadi salah satu penghasil madu terbesar di Indonesia yaitu Riau. Madu hutan yang berasal dari Riau telah banyak diproduksi dan dipasarkan, akan tetapi madu tersebut belum diketahui kualitasnya sesuai dengan standar Nasional yang telah ditetapkan. Oleh karena itu perlu dilakukan pengujian lebih lanjut terkait kadar madu sesuai dengan SNI. Parameter kualitas madu sesuai dengan standar antara lain yaitu aktivitas enzim diastase (DN) dengan kadar minimal yaitu 3, kadar HMF maksimal $50 \mathrm{mg} / \mathrm{kg}$, kadar air maksimal $22(\% \mathrm{~b} / \mathrm{b})$. Kadar gula pereduksi dan sukrosa pada madu seharusnya minimal $65(\%$ b/b) untuk gula pereduksi dan maksimal 5 (\% b/b) untuk sukrosa. Kadar abu serta kadar keasaman maksimal $0.5(\mathrm{~b} / \mathrm{b})$ dan 50 (mL $\mathrm{NaOH} / \mathrm{kg}$ ). Cemaran pada madu juga dapat digunakan sebagai parameter, seperti cemaran logam timbal (pb), Cadmium (Cd), Merkuri $(\mathrm{Hg})$, arsen (As) serta cemaran mikroba.

Madu yang digunakan dalam penelitian ini sebanyak 12 jenis yang berasal dari berbagai daerah di Provinsi Riau. Madu tersebut dikarakterisasi secara fisikokimia sesuai dengan SNI. Madu juga diuji sebagai agen antibakteri dalam menghambat pertumbuhan Eschrechia coli dan Staphylococcus aureus. Penelitian ini bertujuan mendapatkan karakteristik madu multiflora asal Riau secara fisik maupun kimiawi sesuai dengan SNI dan menentukan efektifitasnya terhadap Escherichia coli dan Staphylococcus aureus.

\section{BAHAN DAN METODE}

\section{Bahan dan alat}

Bahan yang digunakan dalam penelitian ini antara lain yaitu sampel madu Riau sebanyak 12 sampel (BKL1, KP1, KP2, KP3, KP6, PLW1, RHI1, RHI2, RHU1, RHU2, RHU3 dan RHU4). Bahan lain yang digunakan yaitu Seng asetat $\left(\mathrm{Zn}\left(\mathrm{CH}_{3} \mathrm{COO}\right)_{2} \cdot 2 \mathrm{H}_{2} \mathrm{O}\right)$, kalium feroksianida $\left(\mathrm{K}_{4} \mathrm{Fe} \quad(\mathrm{CN})_{6} .3 \mathrm{H}_{2} \mathrm{O}\right)$, glukosa, alkohol, $\mathrm{NaHSO}_{3} 0,1 \%$, reagen 3,5Dinitro Salisilat, KNa-Tartrat Tetrahidrat, $\mathrm{NaOH}$, Nutrient Agar (NA), Nutrient Broth (NB), bakteri Escherichia coli dan Staphylococcus aureus. Alat yang digunakan neraca analitik, Sprektofotometer, autoklaf, dan moisture balance.

\section{Pengujian HMF (BSN, 2013).}

Prosedur uji HMF mengikuti metode BSN (2013). Sebanyak 5 g madu ditimbang dalam gelas piala kecil, kemudian dimasukkan ke dalam labu ukur $50 \mathrm{~mL}$. Larutan ditambahkan dengan akuades hingga volumenya $25 \mathrm{~mL}$. Pada larutan ditambahkan dengan $0.5 \mathrm{~mL}$ larutan Carrez I, kemudian dikocok serta ditambahkan dengan $0.5 \mathrm{~mL}$ larutan Carrez II. Larutan ditambahkan dengan setetes alkohol untuk menghilangkan busa pada permukaan. Kemudian disaring dan dibuang sebanyak $10 \mathrm{~mL}$ pada saringan pertama. Sebanyak $5 \mathrm{~mL}$ hasil saringan dipipet dan masing-masing dimasukkan ke dalam tabung reaksi. Kemudian dimasukkan sebanyak $5 \mathrm{~mL}$ air ke dalam salah satu tabung contoh dan $5 \mathrm{~mL}$ $0.2 \%$ natrium bisulfit ke dalam tabung yang lain sebagai pembanding. Larutan dikocok hingga tercampur sempurna dan ditetapkan nilai absorban contoh dan pembanding pada panjang gelombang $284 \mathrm{~nm}$ dan $336 \mathrm{~nm}$. Begitu juga dengan larutan pembanding diencerkan dengan cara yang sama menggunakan larutan $\mathrm{NaHSO}_{3}$ $0.1 \%$. Nilai absorban yang diperoleh dikalikan 
dengan faktor pengenceran sebelum perhitungan.

$$
\begin{aligned}
& \operatorname{HMF}\left(\frac{\mathrm{mg}}{100 \mathrm{~g}} \text { madu }\right) \\
& =\frac{(\mathrm{A} 284-\mathrm{A} 336) \times 14,97 \times 5}{\text { Bobot contoh }(\mathrm{g})}
\end{aligned}
$$

\section{Uji gula pereduksi}

Uji gula pereduksi berdasarkan metode Karimah dkk., (2011) dan Oktavia dkk., (2014) dengan modifikasi. Sebanyak 1 g madu ditimbang kemudian dilarutkan dalam $20 \mathrm{~mL}$. Larutan diambil sebanyak $0.1 \mathrm{~mL}$ dan ditambahkan ke dalam $1.5 \mathrm{~mL}$ reagen DNS (Miller 1959). Kemudian larutan dicampur menggunakan vortex dan dipanaskan dalam penangas air dengan suhu $100^{\circ} \mathrm{C}$ selama 5 menit. Setelah itu larutan didinginkan pada air mengalir, diambil sebanyak $0.5 \mathrm{~mL}$ lalu ditambah $15 \mathrm{~mL}$ akuades steril. Larutan dicampur menggunakan vortex dan diukur pada panjang gelombang $540 \mathrm{~nm}$. Hasil yang diperoleh dimasukkan ke dalam persamaan yang telah didapat dari kurva standar kemudian dibagi dengan bobot sampel yang digunakan. Kadar glukosa dihitung dengan cara mengalikan hasil yang diperoleh dengan 100\%.

\section{Uji kadar air madu (Rani et al., 2015)}

Kadar air pada madu dilakukan menggunakan alat moisture balance. Sebanyak $2 \mathrm{~g}$ madu ditimbang ke dalam moisture balance. Setelah itu alat ditutup dan dinyalakan dengan menekan tombol On. Perhitungan kadar air dimulai ketika lampu menyala sampai dengan selesai ketika lampu telah mati.

\section{Uji kadar abu madu (BSN, 2013).}

Sebanyak $2 \mathrm{~g}$ contoh madu ditimbang dan dimasukkan ke dalam cawan porselen yang sudah diketahui bobotnya. Kemudian dipanaskan di atas pembakar, sampai dengan terbentuk arang, lalu diabukan dalam tanur listrik pada suhu maksimum $550{ }^{\circ} \mathrm{C}$ hingga pengabuan sempurna. Setelah itu didinginkan dalam desikator, dan ditimbang sampai bobot tetap.

Perhitungan :

$$
\text { Kadar } A b u=\frac{W_{1}-W_{2}}{W} \times 100 \%
$$

Keterangan :

$\mathrm{W}$ = bobot contoh sebelum diabukan, dalam $\mathrm{g}$; $\mathrm{W} 1=$ bobot contoh + cawan sesudah diabukan, dalam g; W2 = bobot cawan kosong, dalam $g$.

\section{Uji efektifitas madu terhadap mikroba}

Pembiakan bakteri yang digunakan pada pengujian aktivitas anti bakteri madu yaitu Escherichia coli dan Staphylococcus aureus mengikuti metode Natta, et al., (2008) dan Nwankwo, et al., (2014) yang dimodifikasi. Bakteri Escherichia colidan Staphylococcus aureus dibiakkan pada medium NB. Kemudian diinkubasikan selama 24 jam pada suhu $37{ }^{\circ} \mathrm{C}$. Suspensi bakteri dengan konsentrasi $10^{6}$ CFU/mL diambil sebanyak $0.1 \mathrm{~mL}$ kemudian disebarkan pada cawan petri yang telah berisi NA. Madu yang digunakan pada pengujian merupakan empat madu yang telah diklasifikasikan sesuai dengan karakterisasi yang dilakukan. Kemudian disiapkan beberapa kertas cakram dan ditetesi sebanyak $20 \mu \mathrm{L}$ madu dengan variasi konsentrasi $20 \%, 40 \%$, $60 \%, 80 \%$ dan $100 \%$. Kontrol positif yang digunakan yaitu antibiotik amoksilin dengan konsentrasi $0.05 \%$ dan kontrol negatifnya berupa aquades steril. Cakram yang telah ditetesi madu ditempelkan di permukaan agar yang telah ditumbuhi bakteri dan diinkubasi pada suhu $37{ }^{\circ} \mathrm{C}$ selama 24 jam. Aktivitas antibakteri ditentukan berdasarkan zona bening yang terbentuk.

\section{HASIL DAN PEMBAHASAN}

\section{Kadar air madu}

Hasil pengukuran kadar air pada madu menunjukkan terdapat beberapa sampel yang memenuhi SNI (BSN, 2013). Terdapat enam sampel madu yang memiliki kadar air yang sesuai dengan standar yang telah ditentukan (Gambar 1). Madu dengan kode RHU4 memiliki kadar air terendah yaitu sebesar 16.45\%. Madu PLW1 memiliki kadar air sebesar $17.05 \%$, madu RHU3 yaitu sebesar $17.86 \%$, madu RHU1 yaitu sebesar $18.65 \%$ dan madu RHI2 yaitu sebesar 20.56\%. Madu KP1 memiliki kadar air yang hampir mendekati batas maksimal yang ditentukan SNI yaitu sebesar 21.94\%. Sampel madu selain dari kelima sampel yang telah disebutkan mempunyai kadar air melebihi standar yang telah ditentukan. Madu BKL1 memiliki kadar air sebesar $24.59 \%$, madu KP2 memiliki kadar air sebesar $25.30 \%$, madu KP3 yaitu sebesar $22.76 \%$ dan madu KP6 yaitu sebesar $22.03 \%$. Madu RHI1 memiliki kadar air cukup tinggi 
yaitu $26.51 \%$ dan kadar air pada madu RHU2 yaitu sebesar $24.88 \%$.

Hasil pengukuran kadar air pada Gambar 1 menunjukkan bahwa sampel RHI1 memiliki kadar air paling tinggi dan kadar air terendah yaitu sampel RHU4. Terdapat enam sampel yang memiliki kadar air melebihi standar dan enam sampel yang memiliki kadar air kurang dari standar SNI 2013 yang telah ditentukan. Kadar air yang tinggi pada madu dapat mempengaruhi adanya proses fermentasi oleh khamir, sehingga semakin tinggi kadar air pada madu semakin rendah kualitas madu. Umur simpan suatu madu juga dipengaruhi kadar air, kadar air yang tinggi pada madu mempunyai umur simpan yang relatif pendek.

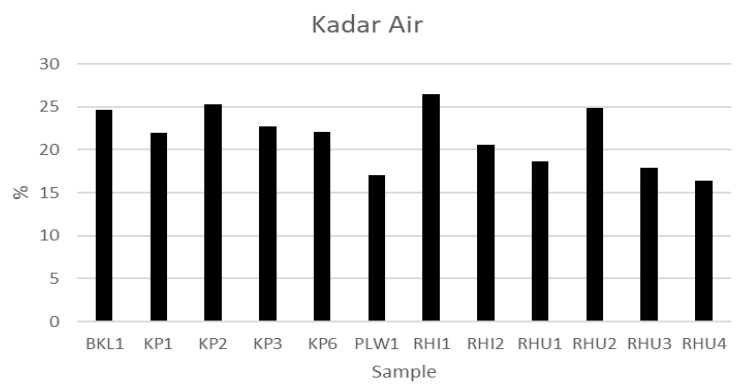

Gambar 1. Hasil pengukuran kadar air madu

Kerusakan madu dapat disebabkan karena terjadinya fermentasi oleh mikroorganisme selama penyimpanan yang dipicu oleh kadar air yang tinggi (Evahelda $d k k$ 2015). Tingginya kadar air madu juga disebabkan karena sifat madu yang mudah menyerap air atau higroskopis dan juga dapat menyerap kelembapan udara di sekitarnya (Suranto 2007). Madu dapat menyerap air sampai 33\% beratnya dalam udara yang lembab. Apabila kadar airnya meningkat maka akan menyebabkan terjadinya fermentasi serta akan menurunkan berat jenis madu tersebut (Maun 1999). Kandungan air pada madu dapat dipengaruhi oleh faktor lingkungan selama produksi seperti cuaca dan kelembaban dalam sarang. Selain itu, kondisi pada nektar serta perlakuan selama ekstraksi madu serta penyimpanannya dapat mempengaruhi kadar air pada madu. Hal tersebut dapat dikurangi sebelum atau sesudah ekstraksi dengan suatu teknik khusus (Gairola et al., 2013). Metode yang telah dikembangkan untuk mengurangi kadar air pada madu yaitu adsorption drying (Maliaentika $d k k$ 2016).

\section{Kadar abu madu}

Madu RHU4 memiliki kadar abu yang paling rendah yaitu sebesar $0.01 \%$, sedangkan kadar abu yang paling tinggi adalah madu RHI2 sebesar $1.01 \%$ (Gambar 2). Hal tersebut dimungkinkan bahwa kandungan mineral pada madu RHI2 paling banyak diantara madu yang lain. Kadar abu pada madu dipengaruhi oleh adanya kandungan mineral yang berasal dari nektar serta sumber makanan lebah yaitu pollen atau serbuk sari. Kandungan mineral utama pada pollen antar lain yaitu kalsium, fosfor, kalium, natrium, besi, magnesium, tembaga dan mangan. Hal tersebut menyebabkan madu memiliki kandungan mineral yang cukup lengkap dengan variasi antara $0.01 \%-0.64 \%$ (Suranto 2007). Menurut Antary dkk (2013), berbagai mineral seperti kalium $(\mathrm{K})$, natrium $(\mathrm{Na})$, magnesium $(\mathrm{Mg})$, besi $(\mathrm{Fe})$, klor $(\mathrm{Cl})$, fosfor (P), belerang (S), serta iodium (I) dan garam radium $(\mathrm{Ra})$ terkandung dalam madu.

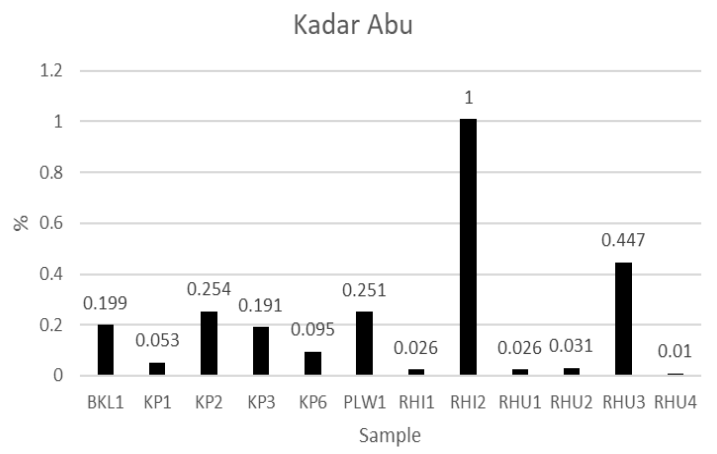

Gambar 2. Hasil pengukuran kadar abu madu

Penelitian Boussaid et al., (2014) menyatakan bahwa secara umum kandungan mineral yang paling banyak pada madu antara lain yaitu kalsium, natrium dan kalium. Madu memiliki kadar mineral yang berbeda-beda tergantung dengan sumber nektar dan pollennya. Madu multiflora umumnya mengandung mineral yang tinggi. Madu dengan kadar mineral yang tinggi umumnya memiliki warna yang lebih gelap (Suranto 2007). Hal tersebut juga ditunjukkan pada madu RHI2 yang memiliki warna lebih gelap dibanding dengan madu RHU4 yang memiliki kadar abu paling rendah (Gambar 3). Kadar abu yang tinggi menandakan tingginya kandungan mineral yang terkandung dalam sampel, namun mineral yang berlebih pada sampel juga tidak disarankan. Kandungan mineral yang berlebih pada madu dapat disebabkan karena proses pengolahan madu yang tidak baik (Antary $d k k$ 2013). Contoh pengolahan madu yang tidak 
baik yaitu pengolahan madu dengan teknik pemerasan manual menggunakan tangan yang umumnya menyebabkan madu tercemar karena kebersihan madu kurang diperhatikan (Yani dan Hernowo 2014).

\section{HMF}

Madu RHI1 memiliki kadar HMF yang paling rendah sebesar 0.70 , dan paling tinggi kadar HMF madu RHU1 sebesar 82.6 (Gambar 4). Kadar HMF yang tinggi pada beberapa madu yang melebihi standar tersebut mengindikasikan bahwa madu telah mengalami proses penyimpanan yang cukup lama atau mengalami proses pemanasan. Sampel madu yang memiliki kadar HMF lebih kecil dari standar dapat dikategorikan sebagai madu dalam kondisi masih segar. Hal ini disebabkan karena HMF merupakan salah satu senyawa hasil dehidrasi dari heksosa yang dapat terbentuk akibat pemanasan pada heksosa. Sesuai pendapat Makfoeld dkk., (2002) bahwa HMF umumnya terdapat pada produk pangan yang peka terhadap panas. Proses terbentuknya HMF dikatalisis oleh suasana asam dengan komponen awal yang terbaik dalam pembentukan HMF berupa fruktosa (Simeonov \& Afonso 2013).

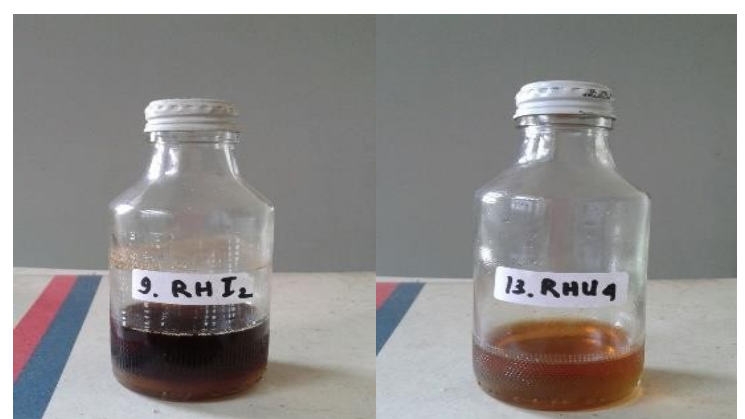

Gambar 3. Perbandingan warna madu RHI2 dan RHU4

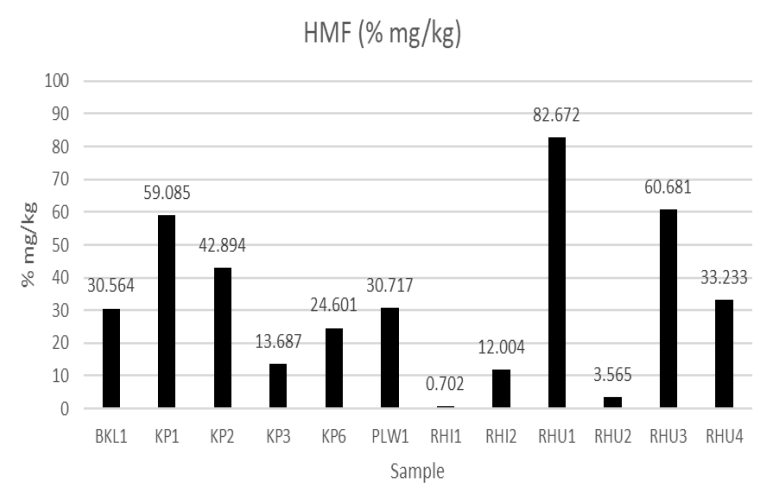

Gambar 4. Hasil pengukuran kadar HMF madu
Madu yang memiliki kadar HMF berkisar antara 30-100 $\mathrm{mg} / \mathrm{kg}$ mengindikasikan madu disimpan dalam kurun waktu yang cukup lama. Kadar HMF lebih dari $150 \mathrm{mg} / \mathrm{kg}$ pada madu mengindikasikan bahwa madu sudah ditambah pemanis buatan. Menurut Shapla et al., (2018), kadar HMF yang rendah pada madu dapat mengindikasikan rendahnya penambahan gula invert pada madu. Kadar HMF yang rendah pada madu juga menunjukkan bahwa madu masih dalam keadaan segar (Boussaid et al.., 2014; Gabor \& Goian, 2006). Chua et al., (2014) menyebutkan bahwa kadar HMF pada madu meningkat setelah dilakukan pemanasan dalam kurun waktu 60 menit. Hal tersebut juga didukung oleh Sukmawati \& Firdaus (2015) yang menyebutkan bahwa indikator yang diperlukan dalam menentukan adanya proses pemanasan pada madu yaitu dengan memperhatikan nilai HMF.

\section{Gula pereduksi (Glukosa)}

Sampel madu yang telah dilakukan uji menunjukkan kadar gula pereduksi yang cukup tinggi (Gambar 6). Kadar gula pereduksi tertinggi dari madu BKL1 yaitu 95.37\% dan terendah madu RHI1 sebesar $69.41 \%$.

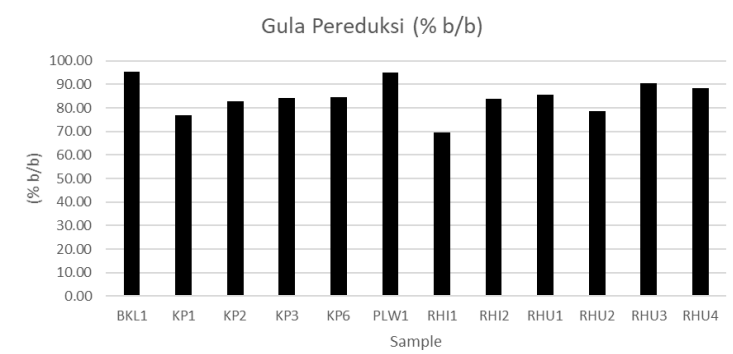

Gambar 5. Hasil pengukuran kadar gula pereduksi madu

Hasil perbandingan dari karakteristik kemudian ditentukan madu yang memenuhi SNI yaitu madu PLW1 dan RHU4. Korelasi antar karakteristik dapat dilihat menggunakan software statistika yang tertera pada Tabel 1 . Nilai korelasi tertinggi yaitu antara kadar air dengan HMF (-0.62). Nilai tersebut menunjukkan korelasi yang cukup, dengan kategori nilai $0.40-0.70$. Menurut Sarwono (2006), nilai korelasi (r) kurang dari 0.20 menunjukkan tidak ada korelasi. Nilai korelasi antara 0.20 hingga 0.40 menunjukkan ada korelasi namun rendah. Nilai korelasi antara 0.40 hingga 0.70 menunjukkan korelasi yang cukup, sedangkan nilai korelasi lebih dari 0.70 menunjukkan korelasi tinggi. Nilai negatif 
menunjukkan korelasi yang berbanding terbalik. Korelasi tersebut menunjukkan bahwa semakin tinggi nilai kadar air maka nilai HMF akan semakin rendah. Kadar air berbanding terbalik dengan gula pereduksi yang ditunjukkan dengan nilai korelasi yang cukup (0.58). Air dan gula pereduksi merupakan komponen utama dalam madu. Semakin tinggi kadar gula pereduksi, semakin rendah kandungan air yang terdapat dalam madu. Nilai korelasi karakteristik yang lain menunjukkan hubungan korelasi yang rendah (Tabel 1).

Batas kadar gula pereduksi pada madu yang telah ditentukan oleh BSN (2013) minimal sebanyak $65 \%(\mathrm{~b} / \mathrm{b})$. Hasil pengukuran kadar gula pereduksi pada sampel madu yang digunakan memenuhi standar yaitu lebih dari $65 \%(\mathrm{~b} / \mathrm{b})$. Kadar gula pereduksi yang paling dominan pada madu yaitu glukosa dan fruktosa. Komponen gula lainnya pada madu yaitu berupa sukrosa dan maltosa (Boussaid et al., 2014). Menurut Aroucha, et al., (2019), kadar gula pereduksi pada madu dipengaruhi oleh lama penyimpanan, semakin lama penyimpanan madu maka semakin tinggi pula kadar gula pereduksinya. Hal tersebut juga dijelaskan oleh Shapla, et al., (2018) bahwa perbedaan waktu penyimpanan madu dapat mempengaruhi kadar gula pereduksinya. Komposisi gula pada madu berpengaruh terhadap sifat-sifat fungsional madu, yaitu kemampuan madu dalam menahan air serta memperpanjang masa simpan. Glukosa dan fruktosa akan mempengaruhi sifat higroskopis madu. Hal tersebut dipengaruhi oleh sumber madu. Selain itu, aspek penting dari komposisi gula dalam madu yaitu kristalisasi. Glukosa dan fruktosa mempengaruhi kecenderungan madu untuk mengkristal (Chayati 2008).

Tabel 1. Nilai korelasi (r) antar karakteristik fisikokimia

\begin{tabular}{lllll}
\hline & $\begin{array}{l}\text { Kadar } \\
\text { Air }\end{array}$ & $\begin{array}{l}\text { Kadar } \\
\text { Abu }\end{array}$ & $\begin{array}{l}\text { Gula } \\
\text { Pereduksi }\end{array}$ & HMF \\
\hline Kadar Air & - & -0.17 & -0.58 & -0.62 \\
Kadar Abu & -0.17 & - & 0.23 & -0.15 \\
Gula & -0.58 & 0.23 & - & 0.34 \\
$\begin{array}{l}\text { Pereduksi } \\
\text { HMF }\end{array}$ & -0.62 & -0.15 & 0.34 & - \\
\hline
\end{tabular}

\section{Perbandingan efektifitas madu terhadap bakteri}

Sesuai dengan parameter uji terdapat empat madu yang terpilih yaitu madu RHU4,
PLW1, RHI1 dan RHI2. Zona hambat paling kecil untuk Staphylococcus aureus yaitu sebesar $7.84 \mathrm{~mm}$ pada madu RHI1 20\% sedangkan Zona hambat terbesar pada madu RHI2 $80 \%$ sebesar $19.25 \mathrm{~mm}$. Zona hambat terkecil Escherichia coli yaitu pada madu RHI1 konsentrasi $40 \%$ sebesar $1.22 \mathrm{~mm}$, sedangkan zona hambat terbesar pada madu PLW1 60\% sebesar $4.58 \mathrm{~mm}$ (Tabel 2).

Kontrol negatif pada uji efektifitas Staphylococcus aureus tidak menunjukkan adanya zona bening, sedangkan kontrol negatif pada Escherichia coli menunjukkan adanya zona bening sebesar $1,90 \mathrm{~mm}$. Kontrol positif pada kedua bakteri menunjukkan adanya zona bening yang terbentuk. Nilai zona bening diperoleh dari selisih diameter zona bening yang terukur dengan diameter cakram yang digunakan. Diameter cakram yaitu sebesar 6 $\mathrm{mm}$. Selanjutnya hasil dari pengukuran zona bening madu dibandingkan sesuai dengan parameter yang telah dipilih. Parameter kadar air terpilih madu RHI1 dan RHU4, parameter kadar abu terpilih madu RHU4 dan RHI2, kadar gula pereduksi terpilih madu PLW1 dan RHI1 yang juga terpilih untuk parameter HMF.

Tabel 2. Hasil pengukuran uji efektifitas madu terhadap bakteri Staphylococcus aureus dan Escherichia coli

\begin{tabular}{|c|c|c|c|c|}
\hline \multirow{2}{*}{ No } & \multirow{2}{*}{ Sampel } & \multirow{2}{*}{$\begin{array}{l}\text { Konsentrasi } \\
(\%(b / v))\end{array}$} & \multicolumn{2}{|c|}{$\begin{array}{l}\text { Rerata Zona } \\
\text { Bening (mm) }\end{array}$} \\
\hline & & & $\begin{array}{l}S . \\
\text { aureus }\end{array}$ & $\begin{array}{l}\text { E. } \\
\text { coli }\end{array}$ \\
\hline \multirow[t]{5}{*}{1} & \multirow[t]{5}{*}{ PLW1 } & $100 \%$ & 18,62 & 2,93 \\
\hline & & $80 \%$ & 15,36 & 3,98 \\
\hline & & $60 \%$ & 15,58 & 4,58 \\
\hline & & $40 \%$ & 13,75 & 2,65 \\
\hline & & $20 \%$ & 10,64 & 4,40 \\
\hline \multirow[t]{5}{*}{2} & \multirow[t]{5}{*}{ RHI1 } & $100 \%$ & 15,38 & 1,95 \\
\hline & & $80 \%$ & 19,76 & 3,26 \\
\hline & & $60 \%$ & 11,76 & 3,51 \\
\hline & & $40 \%$ & 9,68 & 1,22 \\
\hline & & $20 \%$ & 7,84 & 3,08 \\
\hline \multirow[t]{5}{*}{3} & \multirow[t]{5}{*}{ RHI2 } & $100 \%$ & 14,50 & 1,57 \\
\hline & & $80 \%$ & 19,25 & 2,53 \\
\hline & & $60 \%$ & 16,55 & 1,93 \\
\hline & & $40 \%$ & 14,28 & 2,33 \\
\hline & & $20 \%$ & 9,73 & 1,85 \\
\hline \multirow[t]{5}{*}{4} & \multirow[t]{5}{*}{ RHU4 } & $100 \%$ & 13,86 & 3,30 \\
\hline & & $80 \%$ & 15,98 & 3,23 \\
\hline & & $60 \%$ & 13,63 & 1,90 \\
\hline & & $40 \%$ & 14,27 & 3,53 \\
\hline & & $20 \%$ & 10,76 & 2,30 \\
\hline 5 & Kontrol & Amoksisilin & 11,37 & 4,83 \\
\hline
\end{tabular}




$\begin{array}{ll}\text { positif } \\ 6 & \begin{array}{l}\text { Kontrol } \\ \text { negatif }\end{array} \text { Akuades }\end{array}$

dan RHU4 dipilih berdasarkan parameter kadar air rendah dan kadar air tinggi. Hasil menunjukkan madu RHI1 menghambat Escherichia coli lebih kuat yaitu pada konsentrasi 80\%, 60\% dan 20\%. Madu RHU4 lebih kuat menghambat Escherichia coli pada konsentrasi $40 \%$ dan $100 \%$. Zona hambat Staphylococcus aureus lebih kuat yaitu pada penghambatan oleh madu RHI1 dengan konsentrasi $80 \%$ dan $100 \%$, sedangkan madu RHU4 pada konsentrasi $60 \%, 40 \%$ dan $20 \%$.

Perbandingan selanjutnya yaitu madu RHU4 yang memiliki kadar abu rendah dan madu RHI2 yang memiliki kadar abu tinggi. Madu RHU4 lebih kuat terhadap E.coli pada konsentrasi 20\%, 40\%, 80\% dan 100\%. Madu RHI2 menghambat lebih kuat pada konsentrasi $60 \%$. Madu RHI2 lebih kuat menghambat $S$. aureus pada konsentrasi $60 \%, 80 \%$ dan $100 \%$. Berbeda dengan efektifitasnya terhadap E. coli, madu RHU4 hanya mampu menghambat $S$. aureus lebih kuat pada konsentrasi $20 \%$ dan $40 \%$.

Parameter terakhir yaitu perbandingan madu PLW1 dan RHI1. Madu PLW1 memiliki kadar gula pereduksi tinggi dan HMF cukup tinggi, sedangkan madu RHI1 memiliki kadar gula pereduksi rendah dan HMF rendah. Hasil pengukuran zona hambat menunjukkan bahwa madu PLW1 lebih kuat menghambat E. coli pada semua konsentrasi dibanding dengan madu RHI1. Bakteri S. aureus lebih efektif dihambat oleh madu PLW1 pada konsentrasi $20 \%$, 40\%, 60\% dan 100\%. Madu RHI1 lebih efektif menghambat S.aureus pada kosentrasi $80 \%$.

Zona hambat Staphylococcus aureus lebih besar dibanding zona hambat Escherichia coli. Hal ini disebabkan Staphylococcus aureus merupakan bakteri g positif dan Escherichia coli merupakan g negatif. Bakteri g positif mempunyai struktur dinding sel yang tebal yang terdiri atas lapisan peptidoglikan. Bakteri $\mathrm{g}$ negatif memiliki struktur dinding sel yang terdiri atas tiga lapis berupa lipid dan peptidoglikan yang berada pada lapisan kaku. Hal tersebut memudahkan Staphylococcus aureus untuk dihambat. Menurut Nur dkk., (2019), Escherichia coli memiliki susunan dinding sel kompleks yang terdiri atas lapisan peptidoglikan, lipopolisakarida, selain itu terdapat periplasmic space. Periplasmic space memiliki kemampuan untuk menahan membran plasma agar tetap kokoh. Berbeda dengan Staphylococcus aureus yang memiliki struktur dinding sel tebal yang hanya terdiri atas peptidoglikan, sehingga memudahkan senyawa antibakteri untuk menghambat pertumbuhan sel (Nur dkk., 2019).

Hasil pengukuran zona hambat pada Tabel 2 menunjukkan bahwa pengenceran konsentrasi pada perlakuan madu tidak berpengaruh besar terhadap hasil zona hambat yang terbentuk pada kedua bakteri. Pada Staphylococcus aureus zona hambat yang terbentuk yaitu kurang lebih $10 \mathrm{~mm}$, sedangkan Escherichia coli zona hambat yang terbentuk yaitu berada pada rentang $1-4 \mathrm{~mm}$. Hal ini disebabkan adanya indikasi senyawa bioaktif pada madu yang sangat aktif dibuktikan dengan terbentuknya zona hambat yang masih besar pada konsentrasi $20 \%$, sehingga konsentrasi madu perlu dikecilkan untuk mengetahui efektivitas hambatan pada kedua bakteri. Penelitian Fitrianingsih (2014), menyebutkan bahwa madu hitam pahit dan madu hitam manis dapat menghambat bakteri Staphylococcus aureus dan Escherichia coli pada konsentrasi $6,25 \%$ dan $12,25 \%$. Hal tersebut dibuktikan dengan terbentuknya zona hambat yang memiliki rentang sebesar $1-5 \mathrm{~mm}$.

Hasil perbandingan zona hambat pada Tabel 2 menunjukkan bahwa madu RHI1 pada konsentrasi $80 \%$ paling kuat menghambat Staphylococcus aureus dengan zona hambat sebesar $19.76 \mathrm{~mm}$. Madu RHU4 menghambat Staphylococcus aureus pada konsentrasi 80\% yaitu sebesar $15.98 \mathrm{~mm}$. Penghambatan pada Escherichia coli paling kuat yaitu pada madu RHI1 konsentrasi $60 \%$ dan madu RHU4 konsentrasi 40\%. Madu RHI1 dan RHU4 dibandingkan berdasarkan kadar air tinggi dan kadar air rendah. Madu RHI1 memiliki kadar air tinggi sedangkan madu RHU4 memiliki kadar air rendah. Perbandingan hasil penghambatan menunjukkan bahwa madu RHI1 yang memiliki kadar air tinggi menunjukkan zona hambat yang lebih besar dibanding dengan madu RHU4 yang memiliki kadar air rendah. Hal tersebut tidak sesuai dengan pernyataan Krushna, et al., (2007) yang menyebutkan bahwa kadar air yang rendah menunjukkan tingkat penghambatan pertumbuhan bakteri lebih besar.

Hasil zona hambat pada Tabel 2 menunjukkan perbandingan madu RHI2 dan 
madu RHU4. Madu RHI2 memiliki zona hambat terbesar pada konsentrasi $80 \%$ dengan zona hambat sebesar $19.25 \mathrm{~mm}$ untuk S.aureus dan sebesar $2.53 \mathrm{~mm}$ untuk E.coli. Madu RHU4 pada penghambatan $S$. aureus menghasilkan zona hambat terbesar pada konsentrasi $80 \%$ yaitu sebesar $15.98 \mathrm{~mm}$ dan pada penghambatan E.coli menghasilkan zona hambat terbesar pada konsentrasi $40 \%$ yaitu sebesar $3.53 \mathrm{~mm}$. Madu RHI2 merupakan madu yang memiliki kadar abu yang tinggi, sedangkan madu RHU4 memiliki kadar abu yang rendah. Kadar abu tinggi menunjukkan tingginya mineral pada madu tersebut yang diperoleh dari sumber nektar madu. Perbandingan kedua madu ini menunjukkan hasil yang tidak berpengaruh besar terhadap penghambatan kedua bakteri. Perbedaan hasil yang diperoleh pada kedua madu menunjukkan bahwa penghambatan bakteri lebih dipengaruhi oleh kandungan senyawa bioaktif yang terkandung di dalam madu.

Hasil perbandingan pada Tabel 2 menunjukkan madu PLW1 paling kuat menghambat Staphylococcus aureus pada konsentrasi 100\% sebesar $18.62 \mathrm{~mm}$, tapi madu RHI1 menghambat Staphylococcus aureus pada konsentrasi $80 \%$ sebesar $19.76 \mathrm{~mm}$. Pada penghambatan Escherichia coli zona hambat paling besar terbentuk pada kedua madu dengan konsentrasi $60 \%$ yaitu sebesar $4.58 \mathrm{~mm}$ untuk madu PLW1 dan sebesar $3.51 \mathrm{~mm}$ untuk madu RHI1. Madu PLW1 dan RHI1 dibandingkan berdasarkan kadar gula pereduksi dan kadar HMF. Madu PLW1 memiliki kadar gula pereduksi dan HMF yang cukup tinggi, sedangkan madu RHI1 memiliki kadar gula pereduksi dan HMF rendah. Menurut Nadhilla (2014), madu dengan kadar gula pereduksi tinggi cenderung memiliki tekanan osmosis yang tinggi. Tekanan osmosis tersebut akan mengakibatkan mikroorganisme mengalami dehidrasi sehingga tidak dapat tumbuh. Penghambatan kedua bakteri pada madu PLW1 menunjukkan hasil yang tidak berbeda jauh dengan madu RHI1. Penghambatan bakteri tidak hanya dipengaruhi oleh kadar gula yang tinggi dan kadar HMF, namun lebih dipengaruhi oleh senyawa bioaktif yang terkandung di dalam madu.

Perbedaan hasil zona hambat tersebut dapat disebabkan adanya perbedaan kandungan senyawa bioaktif pada tiap madu. Efektivitas penghambatan bakteri oleh madu tidak hanya dipengaruhi oleh karakteristik fisikokimia, namun lebih dipengaruhi oleh senyawa bioaktif pada madu. Kandungan senyawa bioaktif diperoleh dari sumber nektar yang diambil dan diproses oleh lebah madu. Madu multiflora dihasilkan dari beberapa sumber nektar yang beragam, sehingga dapat mempengaruhi kandungan senyawa bioaktif pada madu. Saranraj \& Sivasakthi (2018) menyebutkan madu multiflora lebih mampu menghambat bakteri dibanding dengan madu monoflora karena sumber nektar pada madu multiflora lebih beragam. Madu memiliki senyawa bioaktif berupa flavonoid yang dapat menghambat pertumbuhan bakteri. Menurut Fitrianingsih $d k k$ (2017), aktivitas madu terhadap berbagai mikroorganisme dapat berbeda-beda. Aktivitas antimikroba madu berkaitan dengan senyawa fenolik yang terkandung di dalam madu, meskipun hambatan pertumbuhan bakteri bervariasi. Senyawa lain yang berperan pada aktivitas antibakteri madu yaitu senyawa inhibine. Penelitian Nadhilla (2014) menyebutkan bahwa madu dapat bersifat antibakteri karena adanya senyawa inhibine yaitu hidrogen peroksida $\left(\mathrm{H}_{2} \mathrm{O}_{2}\right)$. Beberapa penelitian, menunjukkan hasil yang berbeda terkait efektifitas madu dalam menghambat bakteri. Menurut Nur dkk., (2019), madu dapat menghambat pertumbuhan bakteri Escherichia coli pada konsentrasi $50 \%$ dan $100 \%$. Berbeda dengan penelitian Nwankwo, et al., (2014), yang menyatakan bahwa madu dapat menghambat pertumbuhan Staphylococcus aureus dan Escherichia coli pada konsentrasi $20 \%$. Penelitian lain menyebutkan bahwa madu dengan konsentrasi $25 \%$ hingga $100 \%$ dapat menghambat pertumbuhan Staphylococcus aureus (Nur dkk., 2019).

\section{KESIMPULAN}

Terdapat 2 madu dari 12 sampel madu yang memiliki karakteristik sesuai dengan Standar Nasional Indonesia (SNI) yaitu madu PLW1 dan RHU4. Madu yang terpilih berdasarkan parameter kadar air, HMF, kadar gula pereduksi, serta kadar abu adalah RHU4, PLW1, RHI2 dan RHI1. Madu RHU4 memiliki kadar air terendah yaitu sebesar $16.45 \%$ dan kadar air tertinggi madu RHI2 sebesar $20.56 \%$. Madu RHU4 memiliki kadar abu paling rendah yaitu sebesar $0.01 \%$ dan kadar abu tertinggi madu RHI2 sebesar 1.01\%. Madu dengan kadar gula pereduksi terendah adalah madu 
RHI1 sebesar $69.41 \%$ dan kadar gula pereduksi tertinggi madu BKL1 yaitu 95.37\%. Madu RHI1 memiliki kadar HMF yang paling rendah yaitu 0.70 dan kadar HMF tertinggi madu RHU1 yaitu 82.67. Zona hambat paling kecil untuk Staphylococcus aureus yaitu sebesar 7.84 mm pada madu RHI1 20\% sedangkan Zona hambat terbesar pada madu RHI2 80\% sebesar $19.25 \mathrm{~mm}$. Zona hambat terkecil Escherichia coli yaitu pada madu RHI1 konsentrasi $40 \%$ sebesar $1.22 \mathrm{~mm}$, sedangkan zona hambat terbesar pada madu PLW1 60\% sebesar 4.58 $\mathrm{mm}$.

\section{DAFTAR PUSTAKA}

BSN. Badan Standardisasi Nasional. SNI 013545-2004. Ics 67.180.10 SNI. 2013. Madu. Badan Standarisasai Nasional. SNI 01-3545-2013. Ics 65.020.99

Antary P.S.S., Ratnayani, K. \& Laksmiwatu, A.A.I.A.M. 2013. Nilai daya hantar listrik, kadar abu, natrium dan kalium pada madu bermerk di pasaran dibandingkan dengan madu alam (lokal). Jurnal Kimia. 7(2),172-180.

Aroucha E.M.M., Silva M.C.P., Leita R.H.L., Santos F.K.G., Oliveira V.R.L., Araujo N.O. \& Silva K.N.O. 2019. Physicochemical, antioxidants and sensorials properties of melipona subnitida honey after dehumidifying. Journal of Food Processing \& Technology. 10(3), 1-6.

Boussaid A., Chouaibi M., Rezig L., Hella R., Donsi F., Ferrari G. \& Hamdi S. 2014. Physicochemical and bioactive properties of six honey samples from various floral origins from Tunisia. Arabian Journal of Chemistry. 30(60), 1-10.

Chayati I. 2008. Sifat fisikokimia madu monoflora dari daerah istimewa Yogyakarta dan Jawa Tengah. AgriTECH. 28(1), 9-14.

Chua L.S., Adnan N.A., Abdul-Rahaman N.L. \& Sarmidi M.R. 2014. Effect of thermal treatment on the biochemical composition of tropical honey samples. International Food Research Journal. 21(2), 773-778.

Evahelda, Pratama F., Malahayati N. \& Santoso B. 2015. Uji aktivitas enzim diastase, kadar gula pereduksi dan kadar air pada madu bangka dan madu kemasan yang dipasarkan di kota palembang. Prosiding.
Seminar Nasional Lahan Suboptimal, Palembang 08-09 Oktober 2015.

Fitrianingsih S..P, Khairat A. \& Choesrina R. 2017. Aktivitas antibakteri madu hitam pahit dan madu hitam manis terhadap Escherichia coli dan Staphylococcus aureus. Jurnal Farmasi Galenika. 1(2), 32-37.

Gabor L. \& Goian M. 2006. Methods of finding counterfeit honeybees. Scientifical papers Faculty of Agriculture XXXVIII. 4th session, Soil Sciences. 301-305.

Gairola A., Tiwari P. \& Tiwari J.K. 2013. Physico-chemical properties of Apis cerana-indica F. Honey from Uttarkashi district of Uttarakhand, India. Journal of Global Biosciences. 2(1), 2-25

Kaligis C.J., Nangoy E. \& Mambo C.D. 2020. Uji efek anti bakteri madu hutan dan madu hitam terhadap bakteri Staphylococcus aureus, Escherichia coli, dan Pseudomonas aeruginosa. eBiomedik. 8(1), 112-119.

Karimah U., Anggowo Y.N., Falah S. \& Suryani. 2011. Oligosakrida madu lokal dan analisis aktivitas prebiotiknya. Jurnal Gizi dan Pangan. 6(3), 217-224

Khairina A. \& Yuanita L. 2015. Pengaruh variasi lama penyimpanan umbi bengkuang (Pachirhyzus erozus) terhadap kadar glukosa darah Rattus norvegicus. UNESA Journal of Chemistry. 4(1), 31-36.

Krushna N.S.A., Kowsalya A. \& Srinivasan R. 2007. Honey as a natural preservative of milk. Indian Journal of Experimental Biology. 45(5), 459-64.

Kuntadi. 2008. Pengembangan budidaya lebah madu dan permasalahannya. Bogor (ID). Pusat Penelitian dan Pengembangan Konservasi dan Rehabilitasi Badan Penelitian dan Pengembangan Kehutanan.

Makfoeld D., Marseno D.W., Hastuti .P, Anggrahaini S., Raharjo S., Sastrowignyo .S, Suhardi, Martoharsono S., Hadiwiyoto S. \& Tranggono. 2002. Kamus istilah pangan dan nutrisi. Yogyakarta (ID): Penerbit Kanisius

Maliaentika S., Yuwono S.S. \& Wijayanti N. 2016. Optimasi penurunan kadar air madu metode adsorption drying dengan response surface methodology (RSM). Jurnal Pangan dan Agroindustri. 4(2), 505-514. 
Maun S. 1999. Pemalsuan madu dengan sakarosa. Jurnal Kedokteran Trisakti. 8(1), 9-19

Miller G.L. 1959. Use of dinitrosalicylic acid reagent for determination of reducing sugar. Analytical Chemistry. 31, 426428.

Nadhilla N.F. 2014. The activity of antibacterial agent of honey against Staphylococcus aureus. Jurnal Majority. 3(7), 96-98.

Natta L., Orapin K., Krittika N. \& Pantip B. 2008. Essential oil from five Zingiberaceae for anti-foodborne bacteria. International Food Research Journal. 15, 337-346.

Nur A., Noor A. \& Sirajuddin S. 2019. Aktivitas antibakteri madu trigona terhadap bakteri G positif (Staphylococcus Aureus) dan bakteri G negatif (Escherichia Coli). Jurnal Kesehatan. 12(1), 134- 40.

Nwankwo C.M., Ezekoye C.C. \& Igbokwe S.O. 2014. Phytochemical screening and antimicrobial activity of apiary honey produced by honey bee (Apis mellifera) on clinical strains of Staphylococcus aureus, Escherichia coli and Candida albicans. African Journal of Biotechnology. 13(23), 2367-2372.

Oktavia F.I., Argo B.D. \& Lutfi M. 2014. Hidrolisis enzimatik ampas tebu (Bagasse) memanfaatkan enzim selulase dari mikrofungi Trichodema reseei dan Aspergillus niger sebagai katalisator dengan pretreatment microwave. Jurnal Keteknikan Pertanian Tropis dan Biosistem. 2(3), 256-262.

Rani P.S, Nagasowjanya $G$, Ajitha A, \& Maheswarrao V.U. 2015. Aquametry the moisture content determination. World Journal of Pharmacy and Pharmaceutical Sciences. 4(8), 566-580.
Saranraj, P. \& Sivasakthi S. 2018. Comprehensive review on honey: Biochemical and medicinal properties. Journal of Academia and Industrial Research. 6(10), 165-181.

Sarwono J. 2006. Metode penelitian kuantitatif dan kualitatif. Yogyakrta (ID) : Graha Ilmu.

Shapla U.M., Solayman Md., Alam N., Khalil Md. I. \& Gan S.H. 2018. Hydroxymethylfurfural (HMF) levels in honey and other food products: effects on bees and human health. Chemistry Central Journal. 12(35), 1-18.

Simeonov S.P. \& Afonso C.A.M. 2013. Batch and flowsynthesis of 5Hydroxymethylfurfural (HMF) from fructose asabioplatform intermediate: an experiment for the organic or analytical laboratory. Journal of Chemical Education. 40(30), 1-3.

Sukmawati N. A. \& Firdaus. 2015. Quality analysis of honey Mallawa parameters based on physical chemistry. Indonesian Journal of Chemical Research. 3, 259262

Suranto A. 2007. Terapi madu. Jakrta (ID) : Penebar Swadaya.

Wilkinson J.M \& Cavanagh H.M.A. 2005. Antibacterial activity of 13 honeys against Escherichia coli and Pseudomonas aeruginosa. Journal of Medical Food. 8(1), 100-103.

Yani N.S.N.F. \& Hernowo. 2014. Perancangan ulang alat pemeras madu. Jurnal Sains, Teknologi dan Industri. 12(1), 16-22. 